\title{
Francesco Petrarca: Zanamstvu
}

\author{
Prevedla Anja Božič
}

Zanamstvu (Posteritati) je nedokončano zadnje pismo v Petrarkovi drugi obsežni pisemski zbirki z naslovom Seniles (1501). Njegova dokončna oblika je nastala ok. leta 1370. Petrarka naj bi ga prvotno načrtoval kot neke vrste apologijo, v katero bi vključil tudi avtobiografske podatke, vendar je kasneje načrt spremenil in se usmeril predvsem $\mathrm{v}$ objavo življenjepisnih informacij. Oblikovno je pismo sestavljeno iz dveh delov: v prvem Petrarka opisuje statično podobo svojega intelekta, značaja in fizičnega izgleda, $\mathrm{v}$ drugem pa $\mathrm{v}$ kronološkem zaporedju podaja pripoved o svojem življenju. Tako z navajanjem premišljeno izbranih informacij in uporabo določenih literarnih vzvodov oblikuje svoj avtoportret, kakršnega je želel prenesti v prihodnje rodove. S tem postane začetnik načrtnega samoupodabljanja $\mathrm{v}$ pismih, namenjenih objavi, in pomembno vpliva na vso kasnejšo pisemsko produkcijo. Prevod je izdelan po elektronski izdaji, ki jo je pripravil Pasquale Stoppelli, Francesco Petrarca, Opera omnia (Rim: Lexis Progetti Editoriali, 1997).

\section{ZANAMSTVU}

Morda si o meni že kaj slišal. A tudi o tem lahko dvomim. Bi nepomembno in dolgo neznano ime lahko prodrlo tako daleč ali se ohranilo toliko časa? Mogoče pa bi rad izvedel, kakšen človek sem bil ali kaj se je zgodilo z mojimi deli, še posebej s tistimi, o katerih si kaj slišal ali pa si ujel zgolj njihove naslove. Če začnem s prvim: ljudje bodo govorili vse mogoče, saj skoraj nihče ne pripoveduje zaradi resnice, temveč iz užitka. Niti hvala niti sramotenje ne poznata mere. Toda bil sem eden izmed vas - navaden umrljiv človeček, nič kaj imenitnega, a ne iz povsem neznanega rodu: bil sem iz starodavne družine, kakor pravi zase cesar Avgust. Po naravi nisem bil krivičen ali neobziren, razen kolikor so mi škodovale nalezljive navade. 
Otroštvo se mi je izneverilo, mladost me je potegnila v svoj vrtinec, odraslost pa me je ponovno spravila $\mathrm{v}$ red in me $\mathrm{z}$ izkušnjami naučila resnice, o kateri sem že dolgo pred tem bral: da so mladostni užitki ničvredni. Seveda, Stvarnik vseh vekov nesrečne in $\mathrm{v}$ prazno napihnjene smrtnike prepušča njihovim tavanjem, vse dokler naposled v zavedanju svojih grehov ne spoznajo sami sebe.

Telesno v mladosti sicer nisem bil preveč močan, obdarjen pa sem bil s precejšnjo spretnostjo. Ne hvalim se z izstopajočo lepoto, a v cvetočih letih me je bilo prijetno pogledati. Bil sem zdrave polti, nekako vmes med bledo in zagorelo, živahnih oči in dolgo nadvse ostrega vida, ki pa me je pri šestdesetih nenadejano zapustil, tako da sem se moral, naj me je to še tako jezilo, zateči k pomoči očal. Vse življenje popolnoma zdravo telo je načela šele starost in ga obkolila z običajno četo bolezni.

Premoženje sem čez vse preziral; ne zato, ker si ga ne bi želel, pač pa ker sovražim napore in skrbi, ki so z lastništvom neločljivo povezane. Prav tako mi ni bilo do prirejanja sijajnih gostij. V skromnosti in ob preprostem živežu sem živel prijetneje kakor vsi Apicijevi oboževalci s svojimi izbranimi banketi. Convivia, kot jim pravijo, mi nikoli niso ugajala, saj požrejo skromnost in uničijo dobre navade. Zdelo se mi je mučno in nekoristno, da bi ljudi vabil s tem namenom, še bolj pa, da bi oni mene. Nasprotno pa mi je nadvse ugajalo jesti v družbi prijateljev, saj me nikoli ni nič bolj veselilo od njihovih obiskov in k jedi nikoli nisem prostovoljno sedel brez družbe. Nič se mi ni zdelo odvratnejše od razkošja, najprej, ker je nekaj slabega in v navzkrižju s skromnostjo, nato pa še, ker je naporno in ogroža spokoj. V mladosti sem trpel zaradi silne, a iskrene, zveste ljubezni, in mučil bi se dlje, ako toplega plamena ne bi ugasila bridka, a pravzaprav blagodejna bolezen. Želel bi si trditi, da odtlej nisem več čutil strasti, vendar bi v tem primeru lagal. Lahko pa zagotovo rečem: čeprav me je ognjevitost v vročici mladosti zapeljala vanje, sem takšne nizkotnosti vedno iz srca preziral. Ko sem bil blizu štiridesetih še dovolj poln močne vneme, sem opustil tako nekdanjo razuzdanost kot tudi vsakršen spomin nanjo, kakor da nikoli ne bi bil pogledal ženske. To štejem med svoje največje uspehe in hvalim Boga, ki me je še mladega in čilega osvobodil cenene sužnosti, ki sem jo tudi sam vedno sovražil. A naj nadaljujem $z$ drugim.

Ponosen sem bil na ostale, ne nase; in ne glede na to, kako nepomemben sem bil v resnici, sem se sam vedno imel za še nižjega. V svoji jezi sem pogosto škodoval sebi, a nikoli drugim. Brez strahu se lahko pohvalim - kajti prepričan sem, da govorim resnico - zelo hitro se vznejevoljim, a tudi naglo pozabim, dobroto pa si dobro zapomnim. Močno sem si želel iskrenih prijateljstev in jih kar najzvesteje gojil. A za starajoče se je to poslednja kazen, saj prepogosto objokujejo umrle bližnje. Imel sem zavidanja vredno srečo s tesnimi odnosi z odličniki in kralji ter prijateljskimi vezmi s plemiči. Vseeno pa sem pred mnogimi, ki sem jih imel zelo rad, zbežal, kajti moja prirojena ljubezen do svobode je bila tako močna, da sem se nadvse vneto izogibal tistim, ki so se že 
po imenu zdeli v nasprotju z njo. Najpomembnejši kralji mojega časa so me imeli radi in so me cenili; zakaj, ne vem, morda bi vedeli oni. $\mathrm{Z}$ nekaterimi izmed njih sem bil v takšnih odnosih, kot da bi bili bolj oni moji gostje kot jaz njihov, in njihov ugled mi nikakor ni bil v nadlego, temveč mi je precej koristil.

Po naravi sem bil prej prizanesljiv kakor duhovit; po značaju sem bil dovzeten za vsak pošten in koristen študij, še posebej pa sem bil naklonjen etični filozofiji in poeziji. Slednjo sem sčasoma zanemaril, ker so me začeli veseliti sveti spisi. V njih sem začutil skrivnostno sladkost, za katero se nekoč nisem zmenil, pesniška dela pa sem shranil le za okras. Poleg mnogih drugih zanimanj sem se posvečal predvsem poznavanju starih časov, saj mi naša sodobnost nikoli ni ugajala. Če bi mi ljubezen do bližnjih ne narekovala drugače, bi si bil vedno želel, da bi bil rojen v katerem koli drugem obdobju. Da bi pozabil sedanjost, sem se v duhu vedno skušal prestaviti v kakšen drug čas in zato me je veselila tudi zgodovina. Kadar sem bil v negotovosti, sem se ravnal po tistem, kar se mi je zdelo najbolj resnično, ali pa mi je verodostojnost zagotavljal piščev ugled. Kljub temu pa me zgodovinska neujemanja niso nič manj motila.

Nekateri so trdili, da je moj način izražanja jasen in mogočen; meni se je zdel nerazumljiv in medel. $\mathrm{V}$ spontanih pogovorih s prijatelji in znanci se $\mathrm{s}$ svojim slogom prav zares nisem ukvarjal in čudil sem se, da je cesar Avgust temu posvečal toliko pozornosti. Kadar pa se je zdelo, da tema, kraj ali sogovornik to zahtevajo, sem se nekoliko bolj potrudil - kako uspešen sem bil pri tem, ne vem; naj presodijo tisti, vpričo katerih sem govoril. V kolikor sem živel pošteno, mi je kaj malo mar, kako sem govoril, kajti sloves, ki temelji le na sijajnem govoru, se ne more dolgo obdržati.

Moji starši so bili spoštovani, izvirali so iz Firenc in so bili srednje premožni oziroma - če sem povsem iskren - je njihov položaj mejil na revščino. Pregnali so jih iz domovine in tako sem se rodil v izgnanstvu v Arezzu; ob zori avgustovskih kalend, 1304. leta te poslednje dobe, ki se je začela s Kristusovim rojstvom. Moje dosedanje življenje se je ali po volji usode ali pa po moji lastni izbiri porazdelilo v naslednja obdobja. V Arezzu, kjer sem prvič zagledal luč dneva, nisem v celoti preživel niti prvega leta svojega življenja - zaradi preklica materinega izgnanstva sem šest let najprej preživel v Ancisi, na očetovem posestvu, kakšnih štirinajst tisoč korakov od Firenc. Svoje osmo leto sem živel v Pisi, deveto in prihodnja leta pa v čezalpski Galiji, v mestu po imenu Avignon, na levem bregu Rena, kjer je rimski papež krščansko Cerkev dolgo ohranjal v sramotnem izgnanstvu in pri tem še vedno vztraja. Pred nekaj leti se je zdelo, kot da jo bo lahko Urban V. premestil nazaj na njen sedež, vendar se iz tega ni nič izcimilo. Kar se mi zdi še huje, občutek imam, kot da zdaj papež, ki še vedno živi, obsoja poštenjakova prizadevanja. Če bi bil Urban V. živel še malo dlje, bi brez dvoma izvedel, kaj sem si mislil o njihovem umiku. Imel sem že pisalo v roki, ko je nenadoma zapustil svoj veličastni položaj in se vdal smrti. Nesrečnež! Toliko bolje bi bilo, če bi lahko 
umrl na svojem domu in pred Petrovim oltarjem! Če bi bili njegovi nasledniki ostali na svojem mestu, bi mu pripadle zasluge za plemenita dejanja; če pa bi odšli, bi njegova krepost toliko bolj sijala, kolikor bolj očitna bi bila njihova krivda. Vendar so takšne tožbe dolgočasne.

Tam, na vetrovnem rečnem bregu, sem torej pod nadzorom svojih staršev preživel otroštvo, nato pa $\mathrm{v}$ primežu svoje domišljavosti celotno mladost. Kljub temu sem dolga obdobja prebil drugje, kajti štiri polna leta sem bil v Carpentri, ki je najbližje mestece vzhodno od Avignona. Na teh dveh krajih sem se naučil tiste nekaj gramatike, dialektike in retorike, kot je mogoče pri tej starosti, oziroma, kot je po navadi naučijo v šolah; in koliko je to, dragi bralec, lahko razbereš sam. Potem sem šel študirat pravo v Montpellier, kjer sem preživel naslednja štiri leta, nato pa ostal še tri v Bologni. Poslušal sem predavanja o civilnem pravu v vsem njegovem obsegu in po mnenju mnogih bi se v mladosti visoko povzpel, če bi bil vztrajal pri začetem. A sam sem študiju obrnil hrbet takoj, ko nisem bil več odvisen od staršev. Razlog ni bil to, da mi pravniški postopki ne bi ugajali - brez dvoma je pravo veličastno in polno starodavnih rimskih zgledov, s katerimi imam veselje - vendar pa je človeška malomarnost pravniško prakso popačila. Tako se mi je bilo zoprno učiti tisto, česar ne bi hotel izvajati v krive namene, a druge izbire skorajda ne bi imel in če bi že ubral pravično pot, bi mojo poštenost pripisali neizkušenosti.

Tako sem se pri dvaindvajsetih vrnil domov. Z besedo dom mislim avignonsko izgnanstvo, kjer sem bival od svojega otroštva; navada je namreč močnejša od narave. Tam sem že postajal znan in vplivneži so si me začenjali želeti med prijatelji. Priznam, da še zdaj ne vem, zakaj, in se čudim. Takrat se namreč nisem, kajti kot je za ta leta običajno, se mi je vsak poklon zdel več kot zaslužen. Med prvimi me je vabila slavna plemiška družina Colonnese, ki je takrat zahajala v rimsko kurijo oziroma bolje rečeno, jo poveličevala s svojo prisotnostjo. Ne vem, kako bi bilo zdaj, a takrat si vsekakor nisem zaslužil tolikšne časti, vabil me je namreč slavni Giacomo Colonna, mož brez para, ki je bil takrat lombezijski škof, in dvomim, da sem kdaj spoznal koga takšnega ali da ga kdaj bom. Vzel me je s seboj v Gaskonijo, kjer sem pod pirenejskimi griči v prijetni družbi gospodarja in ostalih sopotnikov preživel tako nebeško poletje, da ob spominu na tisti čas vedno hrepeneče zavzdihnem. Po vrnitvi sem več let bival v hiši Giacomovega očeta, kardinala Giovannija Colonne, vendar ni bil kakor moj gospodar, pač pa kot oče, ali pa niti to ne, ampak kakor preljubi brat. Pravzaprav je bilo, kot bi stanoval v lastni hiši. Takrat me je mladostno hrepenenje napeljalo k potovanju v Galijo in Germanijo. Čeprav sem si izmislil vse mogoče razloge, da bi potovanje upravičil pred svojimi starši, sem v resnici čutil žgočo željo, da bi videl čim več sveta. Med tem potovanjem sem prvič obiskal Pariz in z užitkom raziskoval, katere zgodbe o tem mestu so resnične in katere izmišljene. Na poti nazaj sem se ustavil v Rimu, ki sem si ga že od otroštva goreče želel videti. Tam sem se poklonil plemenitemu Stefanu Colonni, glavi družine Colonna, ki bi se lahko meril s 
komer koli izmed Starih. Ta me je sprejel k sebi in z mano ravnal popolnoma enako kot s katerim koli izmed svojih sinov. Ljubezen in naklonjenost tega čudovitega moža sta trajali vse do konca njegovega življenja, v meni pa živita še zdaj in ne bosta jenjali vse do moje smrti.

Ob vrnitvi nisem več mogel prenašati prirojenega sovraštva in gnusa do mestnega življenja, še posebej do najostudnejšega izmed mest, in kot bi skušal najti zavetje, sem gledal, kam bi se obrnil. Tako sem kakšnih petnajst tisoč korakov od Avignona odkril ozko, a samotno in očarljivo dolino, imenovano Vaucluse, kjer izvira vladar vseh tokov, Sorgues. Milina tega kraja me je prevzela in pri štiriintridesetih sem se $\mathrm{z}$ vsemi svojimi knjigami vred preselil tja.

Predolgo bi trajalo, če bi nadaljeval s pripovedjo, kaj sem leta in leta počel tam. Izplen je naslednji: skoraj vse, česar sem se lotil, sem tam bodisi dovršil ali začel ali pa vsaj zasnoval, in tega je bilo toliko, da me še zdaj zaposluje in izčrpava. Na razpolago sem imel tako telesne kot umske sposobnosti, vendar me je prej kakor moč prevevala nekakšna vsestranska pripravljenost, zato sem se marsičesa zlahka domislil, a nato opustil, ker mi uresničitev ni šla od rok. Videz tistega kraja me je navdihnil h gozdni poeziji in tako sem se lotil Bukolične pesmi. Dve knjigi O samotnem življenju sem posvetil Filipu, ki je bil vedno velik mož - takrat sicer skromen škof v Cavaillonu, sedaj pa mogočni škofovski kardinal Sabina. On je edini moj še živeči stari prijatelj in do mene nikoli ni čutil ljubezni kot škof, kakor Ambrozij do Avguština, pač pa - in tako je še vedno - kakor do brata.

Ko sem na petek velikega tedna pohajal po tistih gorah, me je prevzela močna želja, da bi napisal epsko pesem s herojsko tematiko o tistem izvrstnem možu, Scipionu Afričanu, čigar čudovito ime mi je bilo že od otroštva blizu. Po glavnem junaku sem knjigo naslovil Afrika in marsikdo jo je občudoval, še preden jo je vzel v roke - na srečo dela samega ali pa na mojo srečo, kajti v svoji raztresenosti zaradi različnih drugih skrbi sem kmalu opustil, kar sem prej začel s tolikšno vnemo.

Med svojim lagodnim bivanjem $\mathrm{v}$ tistih krajih sem nekega dne na svoje veliko začudenje iz rimskega senata in pariške univerzitetne pisarne prejel pismi, ki sta me kot za stavo pozivali eno v Rim in drugo v Pariz, da bi prevzel pesniški venec. V svoji mladostni napihnjenosti in zaradi sodbe tako pomembnih mož sem se imel za vrednega in lastni presoji navkljub sem se ravnal po njihovem mnenju. Vseeno sem nekaj časa premišljal, komu bi ustregel, in tako sem zgoraj omenjenemu Giovanniju Colonni poslal pismo s prošnjo za nasvet. Nahajal se je tako blizu, da sem odgovor prejel že pred tretjo uro naslednjega dne, čeprav sem bil pismo oddal pozno popoldne. Po njegovem nasvetu sem se odločil, da moram podbudam iz Rima dati prednost. Pismi s prošnjo za njegov nasvet in s svojim strinjanjem $z$ njim še vedno hranim. Odpravil sem se torej, in čeprav sem bil, kot je v mladosti navada, sam najprizanesljivejši presojevalec lastnih del, me je oblivala rdečica, pa naj bo zaradi njihovih trditev o meni ali pa zaradi položaja mož, ki so me poklicali 
- pa čeprav tega gotovo ne bi bili storili, če bi mislili, da si prejete časti ne zaslužim.

Odločil sem se, da se bom najprej podal v Neapelj. Tako sem šel k tistemu prevzvišenemu kralju in filozofu Robertu, slavnemu tako po vladanju kot po izobrazbi. V mojem času je bil edini vladar, ki je bil hkrati predan znanosti in kreposti, in želel sem, da bi on sam ocenil moje delo. Še vedno me čudi njegovo ravnanje $\mathrm{z}$ mano in način, kako me je sprejel, kot bi se tudi ti, bralec, če bi vedel. Ko je ugotovil, zakaj sem prišel, se je neverjetno razveselil. Predstavljal si je moje mladostniško zaupanje vanj, morda pa si je mislil, da bo moja čast prispevala tudi k njegovi slavi, saj sem izmed vseh drugih kot edinega verodostojnega kritika izbral prav njega. Kaj bi še govoril? Po številnih raznovrstnih pogovorih sem mu pokazal svojo znamenito Afriko. To ga je tako razveselilo, da je poprosil, naj jo $\mathrm{v}$ zameno za velikodušno darilo posvetim njemu. Tega seveda nisem mogel zavrniti, pa tudi hotel nisem. Poleg tega je določil dan za pogovor o zadevi, zaradi katere sem prišel, s čimer me je zadržal od poldneva do večera. In ker je bilo to premalo časa, snovi za pogovor pa čedalje več, sva enako preživela tudi prihodnja dva dneva. Potem ko je tri dni preizkušal moje neznanje, me je tretjega dne ocenil za vrednega pesniškega venca.

Ponujal mi je kronanje v Neaplju in me dolgo prosil, naj privolim, vendar je ljubezen do Rima premagala tudi vztrajnost tako častitljivega kralja. Ko je sprevidel mojo neomajno naravnanost, mi je dal pismo in spremstvo odposlancev, ki naj bi rimskemu senatu prenesla njegovo nadvse naklonjeno sodbo o meni. To kraljevo mnenje se je takrat ujemalo $\mathrm{z}$ vsesplošnim, predvsem pa mojim lastnim prepričanjem, a danes ne odobravam ne njegove ne svoje presoje, niti enakega mišljenja vseh drugih. Ljubezen in naklonjenost mladosti sta zaslepila njegovo resnicoljubje.

Naposled sem prispel, in kakor koli že nezasluženo, sem v trdnem zaupanju v sodbo tolikih mož in na veliko veselje Rimljanov, ki so lahko prisostvovali slovesnosti, jaz, dotlej preprost študent, prejel pesniški venec. O tem sem pisal tudi v drugih svojih pismih, tako proznih kot verzificiranih. Venec sicer ni imel nikakršnega učinka na moje znanje, pač pa je precej vplival na zavist drugih - a ta zgodba je predolga, da bi jo lahko povedal tu.

Po odhodu iz Rima sem odšel v Parmo in nekaj časa preživel s člani družine Corrigia, ki so bili z menoj nadvse prijazni in velikodušni, med seboj pa precej sprti. Mestu so vladali s takšnim režimom, kot ga nihče od prebivalcev ne pomni in ga $\mathrm{v}$ zdajšnjem času po mojem mnenju ne bo več.

$\mathrm{V}$ misli na čast, ki sem jo vzel nase, in v skrbi, da bi se komu zdela nezaslužena, sem nekega dne, ko sem med gorskim vzponom prek reke Enzo po naključju prišel na ozemlja Reggia, ki se imenujejo Selva Piana, prevzet zaradi lepote tega kraja nenadoma ponovno začel pisati Afriko, ki sem jo bil prej opustil. V navdušenju sem z gorečo vnemo, ki se mi je prej že zdela ugasla, že istega dne spisal nekaj verzov in prav tako vsak naslednji dan, dokler se 
nisem vrnil v Parmo. Našel sem odmaknjeno in mirno hišo, ki sem jo kasneje kupil in jo imam še sedaj. Tam sem svoje delo nadaljeval s tolikšnim žarom, da se še zdaj čudim, kako hitro sem ga dokončal.

Nato sem se vrnil k potoku Sorgues v čezalpsko samoto. Precej kasneje sem si zaradi svojega ugleda v javnosti pridobil naklonjenost odličnega moža, Giacoma Carrare Mlajšega. Ne vem, če dandanes obstaja kdo, ki bi se lahko kosal z njim; pravzaprav vem, da ga ni. Neprestano me je več let nadlegoval s pismi in odposlanci vse do Onstranske Galije, kadar sem bil tam in kjer koli sem se nahajal v Italiji, da bi sprejel njegovo prijateljstvo. Tako sem sklenil oditi k njemu in ugotoviti, kaj pomeni tolikšna vztrajnost tega mogočnega, a meni neznanega moža, četudi nisem mislil, da bo kaj iz tega. Dolgo časa sem se zadržal v Parmi in v Veroni, kjer so me, hvala Bogu, povsod cenili precej bolj, kot bi si zaslužil. Tako sem v Padovo prispel precej pozno. Tam me je ta preslavni mož sprejel ne kot smrtnika, pač pa kot blaženega v nebesih. Tolikšnega veselja, nepopisnega spoštovanja in ljubezni si ne drznem opisati z besedami, zato moram o tem molčati. Vedel je, da sem bil že od otroštva zvest Cerkvi, in da bi me še tesneje povezal s seboj in s svojim domačim mestom, je dosegel, da sem bil izvoljen za kanonika v Padovi. Ko bi bilo njegovo življenje daljše, bi naposled tu sklenil vse svoje blodnje in popotovanja.

Toda glej, pri smrtnih ni nič večnega in vsakršna sladkost, ki se pojavi, kmalu najde trpek konec. Manj kot dve polni leti je odpuščal meni, domovini in svetu, nato pa ga je Bog vzel k sebi; kajti - in ne slepi me ljubezen do njega - vredni ga nismo bili niti jaz niti njegova domovina niti svet. Čeprav je bil njegov sin, ki ga je nasledil, nadvse pameten in ugleden mož ter me je po očetovem zgledu vedno spoštoval, sem se po smrti njegovega očeta, s katerim sem se predvsem zaradi bližine v letih bolj ujel, vrnil v Galijo. Nisem se mogel ustaliti. Ni mi šlo toliko za to, da bi ponovno videl, kar sem videl že tisočkrat, pač pa sem kot kakšen bolnik upal, da bo menjava bivališča odpomogla mojemu naveličanemu razpoloženju. 